\title{
$-O$ Welfare Effects of Adverse Weather through Speed Changes in Car Commuting Trips
}

\author{
Muhammad Sabir \\ Jos van Ommeren \\ Mark Koetse \\ Piet Rietveld
}




\section{Tinbergen Institute}

The Tinbergen Institute is the institute for economic research of the Erasmus Universiteit Rotterdam, Universiteit van Amsterdam, and Vrije Universiteit Amsterdam.

Tinbergen Institute Amsterdam

Roetersstraat 31

1018 WB Amsterdam

The Netherlands

Tel.: +31(0)205513500

Fax: $+31(0) 205513555$

Tinbergen Institute Rotterdam

Burg. Oudlaan 50

3062 PA Rotterdam

The Netherlands

Tel.: + $31(0) 104088900$

Fax: $+31(0) 104089031$

Most TI discussion papers can be downloaded at http://www.tinbergen.nl. 


\title{
WELFARE EFFECTS OF ADVERSE WEATHER THROUGH SPEED CHANGES IN CAR COMMUTING TRIPS
}

Muhammad Sabir*, Jos van Ommeren, Mark Koetse, Piet Rietveld

VU University, Department of Spatial Economics, Amsterdam, the Netherlands

* Corresponding author: VU University, Department of Spatial Economics, De Boelelaan 1105, 1081 HV, Amsterdam, The Netherlands, E-mail: msabir@feweb.vu.nl.

\section{Acknowledgements}

We would like to thank Erik Verhoef for useful comments and Lennard Horstink for providing the weather data. This research has been supported through Nuffic, the Higher Education Commission of Pakistan, and the research programme 'Climate Changes Spatial Planning'. Jos Van Ommeren would like to thank the Frisch Centre, Oslo Norway for its hospitality and the Netherlands Organisation for Scientific Research (NWO) for funding.

\begin{abstract}
This paper investigates the welfare effect of adverse weather through changes in the speed of individuals' car commuting trips in the entire Netherlands. Weather measurements are local and time specific (hourly basis). As most commuters travel twice a day between home and work, we are able to estimate the effect of adverse weather employing panel data techniques, which is novel in this context. We find that for most commuters the welfare effects of adverse weather conditions are negative but small. However, the commuters' welfare costs due to rain are rather substantial during rush hours in congested areas (and up to 15 percent of the overall commuting costs).
\end{abstract}

August 22, 2008 


\section{Introduction}

Climate change will affect weather patterns all over the world, albeit differently for different regions, and pose important challenges to the world economy (IPCC, 2007). Moreover, the impacts of climate change will vary substantially from sector to sector. A sector that has been largely ignored up till now, but that may be severely affected, is the transport sector. For instance, it is plausible that changing weather patterns will affect infrastructure cost of roads, for example, more frequent rain and higher temperatures may increase maintenance cost of roads (Carmichael et al., 2004). Changes in weather patterns may also have substantial effects on the number and severity of traffic accidents and congestion on roads and airports.

The anticipated change in weather patterns, and in particular the changes in precipitation, have direct implications for the welfare of transport users. Specifically, adverse weather conditions may bring about delays in trips and an increase in traffic accidents. Weather changes may affect transport activities and therefore the welfare of the population in two main ways: (1) it may affect demand for an activity (for example, sunbathing on the beach) and therefore the derived demand for transport directly (for example, going to the beach) and (2) it may affect the welfare of transport users. In the current paper, we are interested in the latter effect.

We will focus on the effect of adverse weather on the travel speed of commuting trips. In the literature it is common to focus on traffic speed measured at the road or road segment level (see, for example, Ibrahim and Hall, 1994), implying that only part of the trip is analysed. This approach is less insightful because it is perfectly possible that weather-induced delays on certain parts of the trip are partially or even completely compensated by higher average speed levels on other parts of the trip. An advantage of this paper is that our 
observations are at the trip level, implying that we focus on the average speed of the whole trip instead of only part of the trip. Furthermore, a focus on commuting is useful, because, in general, demand for employment and therefore demand for commuting hardly depends on weather conditions. The welfare loss associated with a reduction in derived demand is therefore negligible, implying we can focus on the welfare effect of transport users. This most probably does not hold for trips related to other activities, for example, demand for recreational and leisure trips is likely negatively affected by adverse weather conditions. One of the other methodological advantages of focusing on commuting trips is that one can apply panel techniques as for most commuters two trips on the same day are observed. In addition, welfare effects of adverse weather for non-car users are not so much caused by a delay in trips, but more by the inconvenience of adverse weather itself. ${ }^{1}$ For car commuters, the main welfare effects of weather will occur through changes in trip speed, changes in the number and severity of traffic accidents, and changes in travel time reliability. The main objective of the current paper is to analyse welfare effects of adverse weather associated with changes in speed of car commuting trips. For reasons explained later on, the methodological framework used allows for the calculation of welfare effects for this group of travellers. In this paper we will largely ignore the possible welfare effects of adverse weather through changes in travel time reliability. We leave this issue for further research.

Most of the literature available on the effects of weather on road transport focuses on traffic accidents and traffic speed. Empirical studies on the impact of rain and snow on the frequency and severity of road accidents are abundant. Most of the evidence shows an increasing effect of precipitation on the frequency of accidents (see, for example, Eisenberg, 2004; Shankar et al., 2004; Edwards, 1996). The impact on accident severity appears to be not

\footnotetext{
${ }^{1}$ In the Netherlands the main alternative to car is biking (25 percent of commuters) and walking ( 9 percent of commuters) and only about 6 percent of commuters use public transport (Statistics Netherlands).
} 
as pronounced. For instance, using US traffic accident data between 1975 and 2000, Eisenberg and Warner (2005) find that snow days had more nonfatal-injury crashes and property-damage-only crashes, but fewer fatal crashes than dry days. Similarly, Khattak et al. (1998) use an extensive dataset with single-vehicle and two-vehicle traffic accidents in North Carolina in the period 1990 to 1995 . They find that adverse weather (rain, snow, sleet, fog) has a statistically significant but small negative impact on accident severity, that is, accidents are less severe in adverse weather. The effects of a wet and a snowy or icy road surface are much larger, however. The mediating effect in the observed pattern is likely that precipitation, and adverse weather in general, reduces traffic speed, thereby reducing the severity of an accident when it occurs. $^{2}$

Similarly, some studies analyse the impact of weather on traffic speed. For instance, Maze et al. (2006) use a dataset including four years of traffic data from the freeway system in the Minneapolis/St. Paul metropolitan area and weather data from three weather stations nearby the freeway network. They show that adverse weather causes clear reductions in traffic speed; up to $6 \%$ for rain, up to $13 \%$ for snow, and up to $12 \%$ for reduced visibility. Similarly, Ibrahim and Hall (1994) analyse the effects of adverse weather on the speed-flow and flowoccupancy relationships for Canadian travellers (see also Brilon and Ponzlet, 1996; Hall and Barrow, 1988). They find a small but statistically significant effect of light rain and light snow on the free-flow speed. The effect of heavy rain and heavy snow are much larger, causing a reduction in the free-flow speed of $5-10 \mathrm{~km} / \mathrm{hour}$ and $38-50 \mathrm{~km} / \mathrm{hour}$, respectively.

To estimate the welfare effect of weather through changes in traffic speed, we use information on the average value of travel time (see, for example, Small and Verhoef, 2007). Based on a meta-analysis of 56 value-of-time estimates from 14 different countries, Waters (1996) finds an average ratio of value of time equal to 48 percent of gross wage rate and a

\footnotetext{
${ }^{2}$ Plausibly, car drivers reduce the risk of accidents by adjusting their speed level, so the effect of weather on speed will indirectly affect costs associated with traffic accidents.
} 
median ratio of 42 percent for commuting trips made by automobile. In another review, Wardman (1998) finds similar values. In the Netherlands, gross hourly wage rates for car commuters are about $16 €$, suggesting a value of time of about $8 €$ per hour. $^{3}$

In this paper we add to the literature in a number of ways. First, we use weather data that are local and measured on an hourly basis. Second, we make use of panel data techniques, which have not been used in this context, thereby avoiding confounding effects. Third, we derive welfare effects related to changes in traffic speed caused by weather condition variations. Finally, our observations are at the trip level, allowing us to focus on the effects of adverse weather on the average speed of the whole trip, instead of only part of the trip as is common in the literature (see Ibrahim and Hall, 1994).

The remainder of this paper is organised as follows. Section 2 discusses the empirical model and the econometric methodology to derive welfare effects of weather through changes in commuting speed. Section 3 discusses the data as well as the explanatory variables included in the model. Section 4 provides the empirical results and discusses the welfare effects of adverse weather conditions for the Netherlands. Finally, Section 5 concludes.

\section{Theory and estimation method}

\subsection{Theoretical background}

Our empirical analysis is based on standard micro-economic theory such as used in Van Ommeren and Dargay (2006), who derive a structural model for commuting speed and then use that model for Great Britain. This model is also used in Fosgerau (2005) who applies it to

\footnotetext{
${ }^{3}$ This has been calculated using Dutch National Household Survey of household including employees who commute by car.
} 
Denmark. ${ }^{4}$ It is assumed that utility is a concave function of speed and that increasing speed is costly (for example, due to higher risk of accidents, fines, etc). Further, it is assumed that the cost function is a convex function of speed. It can then be shown, quite intuitively, that the optimal speed is chosen such that the marginal benefits of speed (a reduction in travel time given the distance) equals the marginal costs of speed..$^{5}$ Given the assumption that the monetary costs are a power function of speed, it can be shown that the double-log model is the preferred statistical model.

Now suppose that weather conditions deteriorate (for example, an increase in rain), leading to an increase in the marginal costs of speed (for example, due to more accidents). The commuter will decrease his or her speed level, which induces a loss in travel time. Due to rain the commuter will therefore not only experience a reduction in welfare through a loss in travel time but may also experience loss in welfare due to higher marginal costs of speed (for example, due to the increased risk of accidents). ${ }^{6}$ Hence, adverse weather conditions will not only induce increases in travel time, but will also affect other (difficult to observe) costs. So, in general, the welfare effect of adverse weather conditions will differ from the welfare loss associated with the time increase. We will focus on the effect through time losses only.

Van Ommeren and Dargay (2006) show that the marginal effect of an exogenous environmental characteristic, such as weather, on the logarithm of speed can be interpreted as the marginal effect of this characteristic on the logarithm of the commuter's total commuting costs (the sum of travel time costs and other costs that vary with speed). Given an estimate of average commuter value of time, it is meaningful to estimate the welfare consequences of a

\footnotetext{
${ }^{4}$ We improve on the statistical analyses of Fosgerau (2005) and Van Ommeren and Dargay (2006) by explicitly taking the time dimension of the moment of travel (in time of days, hours) into account as well as unobserved heterogeneity of commuters.

${ }^{5}$ Another consequence of the Van Ommeren and Dargay (2006) model is that the logarithm of distance and income affect the logarithm of speed. We follow this specification.

${ }^{6}$ Intuitively, in the new equilibrium, the marginal accident cost must be higher as the marginal benefits of speed are also higher.
} 
loss in travel time. In the current study we use a value of $8 €$ per hour, which is about 50 percent of the gross hourly wage in the Netherlands, in line with the literature. For our empirical analyses we will use the following logarithmic specification, which is in line with the theoretical considerations above:

$$
\log \left(S_{i t d}\right)=\beta_{0}+\beta_{1} W_{i t d}+\beta_{2} \log \left(D_{i t d}\right)+\beta_{3} \log \left(y_{i}\right)+\beta_{4} X_{i}+\beta_{5} F_{t d}+\xi_{i t d}
$$

where subscript $i$ represents individuals, $t$ represents hour of departure and $d$ represents day of the year. Furthermore, $S$ is speed, $W$ is a vector of individual-specific time-varying variables (including weather variables), $D$ denotes the distance travelled, $y$ is the income of individuals, $X$ is a vector of individual variables (including gender, age, etc), and $F$ refers to time-specific characteristics such as degree of urbanisation, hour of travel, day of the year and seasonal variation. Finally, the $\beta$ 's are parameters to be estimated by the model and $\xi$ denotes an unobserved error term.

\subsection{Assumptions regarding conditions of error terms}

In order to analyse the impact of weather on the speed of commuting trips we use different econometric models. The models estimated make different assumptions about the unobserved error term $\xi$ and therefore have different interpretations. The first model is the OLS model, with the standard assumption that the errors are independent. This implies that if a person makes two trips on the same day then the errors of both trips are assumed to be independent. This is a strong assumption which most likely does not hold in the current case. As a result, OLS generates inefficient estimates (Wooldridge, 2003). Therefore, random effects panel data models that control for the correlation between errors are employed. In addition, OLS does not control for unobserved differences in preferences among individuals and other unobserved features of individuals (such as the exact location of the individual). 
Likely these unobserved features are correlated to some of the weather variables. Clearly, weather itself is not correlated to any unobserved individual specific variable, but the interaction of weather with other explanatory variables (such as region) is likely correlated to unobserved individual-specific variables. Since we are interested in the interaction effect of adverse weather with congestion variables this poses a problem. For this reason we include individual specific fixed-effects, which also controls for selection effects that may occur since we have a selected sample of car commuters. ${ }^{7}$

For the same reasons as discussed above it may be relevant to control for day-specific and hour-specific random and fixed effects. For instance, it is plausible that all commuters are affected by a common factor on the same day (apart from weather), which is correlated with weather (for example, summer holidays reduce traffic). Similarly, it is plausible that all commuters are affected by a common factor during the same hours, which is correlated with weather patterns (for example, temperature tends to be higher during the day than during the evening rush hour). Ultimately, we estimate fixed and random effects panel data models with day-specific, individual-specific and hour-specific effects. ${ }^{8}$ Fixed effects models include a dummy variable for each observation in the same group (where a group refers to either an individual, a day or an hour), whereas random effects allow for correlation between the observations in the same group.

\footnotetext{
${ }^{7}$ Individual fixed effects may pick up differences between individuals that are actually caused by adverse weather. For example, when an individual commutes twice and both times in rainy conditions, and another also commutes twice but under dry conditions, the differences in speed between these two individuals are fully picked up by the fixed effects and not by the rain dummy. Note that this does not affect the consistency, but only the efficiency of the estimated coefficients.

${ }^{8}$ Note that some commuters have two different distances on the same day, which allows us to identify the effect of distance using individual fixed-effects.
} 


\section{Data and model specification}

The data used in this paper are taken from two sources. We make use of the National Transport Survey provided by Statistics Netherlands for $1996 .{ }^{9}$ Over the course of an entire year, more than 150,000 individuals were asked to fill out a questionnaire containing 77 different questions about their travel behaviour (all trips) during a single day and about important individual and household characteristics. The dataset contains more than 628,000 reported trips. For most commuters we observe two commuting trips a day. For some commuters we only observe one commuting trip (predominantly due to underreporting of one of the trips) while for others we observe more than two commuting trips (for example, for workers with multiple jobs or who go home for lunch).

The second data source is a weather database available from the Royal Netherlands Meteorological Institute (KNMI) for 1996. It contains weather conditions on a hourly basis for 32 weather stations spread all over the Netherlands. We use the weather conditions from the weather stations which are nearest to commuters' places of departure (in almost all cases). The average distance to a weather station is about 12 to $13 \mathrm{~km}$, which means that our measurement of weather conditions is very local. ${ }^{10}$ This is particularly important as the incidence of rain, which as we will see is the most important weather determinant of commuting speed, is known to be local especially during the summer months. The weather conditions refer to temperature (we distinguish between temperatures above and below zero), wind speed (wind strengths exceeding 6 Beaufort), rain and snow. ${ }^{11}$ Hence, by combining

\footnotetext{
${ }^{9}$ We used the year 1996 for our analysis (and not a more recent year) because for this year we have more detailed information about weather conditions.

${ }^{10}$ We have estimated the average distance as follows: The total land area of the Netherlands is 33,889 $\mathrm{km}^{2}$. Given the assumption that stations are homogenously spread over the country and each weather station covers a circle, the maximum distance is $18.78 \mathrm{~km}$. The average distance of a circle is $2 / 3$ of the maximum distance, so the average distance to a station is $12.52 \mathrm{~km}$.

${ }^{11}$ Snow is measured as the interaction effect of rain and temperature equal to or below $0^{\circ} \mathrm{C}$.
} 
these two data sources, we are able to measure for each commuting trip the local weather conditions of the hour in which the trip took place.

As alluded to in the introduction, we select only car commuting trips for our analyses. This has a number of economic and statistical reasons. First, and most importantly, we select commuting trips because the demand for commuting is derived from the demand for labour, which does not directly depend on weather, whereas the derived demand for other trips (in particular, leisure trips) are affected by adverse weather. Hence, for commuting trips, interpretation of the welfare effect of weather is more straightforward. Second, commuting distance can be instrumented avoiding problems with the endogeneity of distance to speed, whereas this may be more difficult for other travel purposes (Van Ommeren and Dargay, 2006). Third, we select car trips because for other modes, and in particular cycling, which is the main alternative for car use in the Netherlands, the welfare of commuting is directly affected by the weather and not so much through its effects on traffic speed. A possible critique on our sample selection is that it may generate biased estimates (for example, Wooldridge, 2003). However, by using panel data estimation techniques we are able to deal with this issue.

Given these restrictions, our sample contains 42,534 car commuting trips made by 17,248 commuters. Average trip distance is $20 \mathrm{~km}$, average speed is $43.9 \mathrm{~km} / \mathrm{h}$ and average commuting time is 24.5 minutes. The means and standard deviations of other explanatory variables are provided in Appendix A. Most explanatory variables included in the model are self-explanatory and are included to control for differences in 'demand' for speed (for example, gender) as well as for environmental characteristics (for example, degree of urbanisation). Some variables need some additional explanation. Van Ommeren and Dargay (2006) use the wage rate in the specification of their theoretical speed model but, because of lack of data on wages, they use individual income for their empirical analysis. We will also 
use individual income instead of the wage rate for the same reason. Further, we control for rush hours (morning and evening rush hours) to capture congestion effects. ${ }^{12}$ Furthermore, adverse weather may have stronger effects on speed during rush hours. The interaction of (morning and evening) rush hours and rain are therefore included in the model. ${ }^{13}$

We also control for speed differences in congested areas by distinguishing between trips towards and from the Randstad. ${ }^{14}$ Furthermore, we interact the congestion variable with rush hour as well as with a rain dummy, as one may expect that rain may have stronger negative effects during rush hours on congested roads. In order to control for carpooling effects, we control for the number of people in the vehicle (Rietveld et al., 1999). Seasonal effects are captured by seasonal dummy variables.

\section{Results}

The results of the various model estimations are provided in Tables 1 and 2. In Table 1 we provide the results for a specification where the weather variables are not interacted with any other variable. This specification provides the main effects of the weather variables. Table 2 provides the results of a similar model with two weather-variable interaction effects. In general, the results are robust with respect to model specification and the type of model

\footnotetext{
${ }^{12}$ In a separate analysis, we distinguish between morning and evening rush hours. The results are almost identical and can be provided on request. Morning rush hours are defined as trips between 05:00 and 09:00 and evening rush hours between 15:00 and 18:00.

${ }^{13}$ In the results produced here, we include interaction effects for the rain variable but not for temperature and wind, because the main effects of these variables are small. In addition, inclusion of more interaction effects makes interpretation of the effects cumbersome.

${ }^{14}$ The Randstad consists of a ring of four largest cities of the Netherlands (Amsterdam, Utrecht, Rotterdam and the Hauge) and their surrounding areas. The population of the Randstad is over seven million inhabitants which is almost 50 percent of total population of the country. The Randstad contains the main centre of employment and business activities, so in the morning, congestion occurs on roads towards the Randstad and in the afternoon on roads from the Randstad.
} 
estimated. ${ }^{15}$ The signs and magnitudes of the effects are comparable across the models with few exceptions. ${ }^{16}$

$$
<<<\text { Table } 1 \text { around here }>>>
$$

The results in Table 1 suggest that on average adverse weather conditions have a rather limited impact on car commuting speed. A notable exception is the occurrence of snow, which reduces speed by about 7 percent. There appears to be no relationship between temperature and speed. Commuting trips made during strong winds, that is, wind strengths higher than 6 Beaufort (bft), are on average about 3 percent slower. Similarly, the rain coefficient suggests a minor reduction in traffic speed in rainy conditions. Hence, although there appear to be negative welfare consequences of adverse weather conditions, in general the welfare costs are close to negligible except for snow. To estimate the welfare costs we focus on the average commuter. For this commuter the average commuting time is 0.39 hour (see Appendix A). Therefore, the welfare effect of snow through time loss is about 22 eurocent $(.39 \times .07 \times 8 €)$ per commuting trip.

Some interesting patterns can be observed for the estimated effects of other explanatory variables. It appears that carpooling has a strong negative effect on speed in the order of about

\footnotetext{
${ }^{15}$ In particular, we have focused on heteroskedasticity. Adverse weather may not only affect average speed but also speed variation. In the log linear model the estimated standard error of residuals has a direct effect on estimated expected traffic speed, which implies that adverse weather may also have an effect through the standard error of residuals. In order to analyse whether this is the case we allow the variance of the error term to vary with weather and several other variables in the model with individual-specific fixed effects. This exercise shows that adverse weather has only a small and statistically insignificant effect on the standard error of residuals. Consequently, our estimates are robust with respect to the specification of the variance.

${ }^{16}$ At the bottom of both tables the correlation between group-specific error terms are provided for the random effects models. The strong correlation observed for the individual-specific and hour-specific random effects models indicates that correlation between errors is potentially a more important statistical issue for these models then that for day-specific random effects model.
} 
six percent, which suggests that carpooling is an important determinant of car commuting speed due to the implied waiting or detours. Furthermore, the degree of urbanisation strongly reduces trip speed, with a more than 16 percent speed reduction in very urbanised areas (see also Van Ommeren and Dargay, 2006). The effects imply up to 16 percent speed reductions in urbanised areas. This result is plausible, as trips made in urban areas experience more congestion, more road signals, crossing points, etc. as compared to trips made in rural areas. Trips made during rush hours are 3 to 7 percent slower and older people drive slower. Males commute 3.5 percent faster than females, which is consistent with the literature (Rietveld et al., 1999; Van Ommeren and Dargay, 2006). The trips made during weekends are faster as compared with working days. In contrast to Fosgerau (2005), who also focuses on car commuting trips, we failed to find a statistically significant positive effect of income on speed. Furthermore, we find that the distance elasticity is around .40 to .44 (in line with Van Ommeren and Dargay, 2006).

\section{$<<<$ Table 2 around here $>>>$}

The interaction effects of rain and rush hours are negative but statistically significant only in the hour-specific random effects model, which shows a 2.3 percent reduction in speed. ${ }^{17}$ This finding seems in line with our previous finding that rain has only a small negative welfare effect on speed. One of the most interesting findings is that commuting trips made during rush hours in congested areas are substantially and negatively influenced by rain. ${ }^{18}$ The impact of rain on speed reduction for these trips ranges between 10 to 15 percent. Hence, the welfare loss of rain when commuters face congested roads turns out to be

\footnotetext{
${ }^{17}$ In the hour-specific effects model with interaction effects, one may not identify the rush hour variable as it is an hour-specific variable.

${ }^{18}$ Recall that congestion is defined for trips made during morning rush hours toward the Randstad and for trips made during evening rush hours out of the Randstad. This refers to 3.3 percent of all trips. Likely, more refined measures of congestion would have generated more pronounced effects of the interaction of rain and congestion.
} 
substantial and between 10 to 15 percent of total commuting costs. Note that the average commuting time of trips in congested areas during rush hour is .73 hours (see Appendix A). This means that the average welfare loss related to increases in travel time due to rain is about 88 eurocent $(.73 \times 8 € \times .15)$ per commuting trip in congested areas during rush hour, which we consider to be substantial. ${ }^{19}$

It may be argued that the distance variable included in the model is endogenous since the distance travelled may depend on speed (Van Ommeren and Dargay, 2006). In order to address this problem the model has been re-estimated by instrumental variables (IV), using the education of commuters as an instrument of distance. The results of OLS and IV are almost identical, so the IV estimates are not reported here. ${ }^{20}$ We have also investigated other weather variables (such as sunlight) but did not find any effect. Furthermore, our results are robust by selecting sub-samples (such as the selection of commuters that are observed exactly twice).

\footnotetext{
${ }^{19}$ One may argue that our estimates of the effect of bad weather on welfare is an underestimate of the real welfare effect, because we have ignored the welfare effects of increased unreliability and arrival times at work due to bad weather. To test for the presence of unreliability, we have estimated a linear speed model with heteroskedasticity due to adverse weather. These analyses show that rain during peak hour strongly increases the variance, but this effect largely disappears for the fixed-effects model. These results suggest that adverse weather increases between-day unreliability but does not increases within-day unreliability. We have attempted to estimate the welfare losses of increased unreliability, making use of the conceptual framework of Small (1982). According to this model, increased unreliability in travel times implies that workers leave earlier from home in order to be at work in time. To address this issue, we have estimated the effect of the weather variables on the morning departure time of the car drivers (after six o'clock and before 12 o'clock). Hence, the dependent variable is a duration variable. The explanatory variables included are the individual (including commuting distance) and household variables (including the urbanisation degree of the region of residence) that were included in the previous analyses, as well as the weather variables which are allowed to vary by hour. Clearly, the hazard rate of departing time varies strongly by hour. We have therefore estimated semi-parametric duration models using a partial likelihood approach, as these models do not require any parametric assumptions on the effect of hour time on the departure time (see Lancaster, 1990). Our estimates do not show any evidence that bad weather makes people depart earlier for work. In fact, we even find a small positive effect of snow on the departure time (workers leave about five minutes later). This finding is consistent with the studies by Arnott et al. $(1991,1999)$ as well as De Palma and Lindsey (1998) which analyse a stochastic bottleneck model.

${ }^{20}$ The IV estimates can be received upon request.
} 


\section{Conclusions}

In this paper we analyse the effects of weather on the speed of car commuting trips for the Netherlands. We use micro data at the trip level based on the national transportation survey and detailed local time-specific weather conditions for the Netherlands for the year 1996. We estimate a standard OLS regression model as well as panel data models with fixed and random effects. We use a large number of explanatory variables in our models such as distance travelled, age, gender, degree of urbanisation, income, and hour of the day. Our main interest, however, is in the effect of weather variables such as temperature, rain, snow, and wind strength. We also include interaction effects of the weather variables with congestion specific variables. We have taken the potential endogeneity of distance into account.

In general the results are robust with respect to model specification and type of model estimated. The estimates show that wind strength negatively affects the speed of car commuting trips. Compared to normal wind conditions, strong winds reduce traffic speed by about 3 percent on average. Snow has a more substantial negative effect of around 7 percent. We are not able to identify any effect of temperature. Although the average effect of rain appears to be small, rain does have a strong negative effect on trip speed during rush hours in congested areas. The welfare effect of rain for these trips ranges between 10 to 15 percent of total commuting costs and amounts to at least 88 eurocent per commuting trip.

\section{References}

Arnott, R., A. de Palma, and R. Lindsey (1991): 'Does Providing Information to Drivers Reduce Traffic Congestion?', Transportation Research Part A, 25, 309-318. 
Arnott, R., A. de Palma, and R. Lindsey (1999): 'Information and Time-of-Usage Decisions in the Bottleneck Model with Stochastic Capacity and Demand', European Economic Review, 43, 525-548.

Brilon, W. and M. Ponzlet (1996): 'Variability of Speed-Flow Relationships on German Autobahns', Transportation Research Record, 1555, 91-98.

Carmichael, C. G., W. A. Gallus, B. R. Temeyer, and M. K. Bryden (2004): ‘A Winter Weather Index for Estimating Winter Roadway Maintenance Costs in the Midwest', Journal of Applied Meteorology, 43, 1783-1790.

De Palma, A. and R. Lindsey (1998): 'Information and Usage of Congestible Facilities under Different Pricing Regimes', Canadian Journal of Economics, 31, 666-692.

Edwards, J. B. (1996): 'Weather-Related Road Accidents in England and Wales: A Spatial Analysis', Journal of Transport Geography, 4, 201-212.

Eisenberg, D. (2004): 'The Mixed Effects of Precipitation on Traffic Crashes', Accident Analysis and Prevention, 36, 637-647.

Eisenberg, D. and K. A. Warner (2005): 'Effects of Snowfalls on Motor Vehicle Collisions, Injuries, and Fatalities', American Journal of Public Health, 95, 120-124.

Fosgerau, M. (2005): 'Speed and Income', Journal of Transport Economics and Policy, 39, $225-240$.

Hall, F. L. and D. Barrow (1988): 'Effect of Weather on the Relationship Between Flow and Occupancy on Freeways', Transportation Research Record, 1194, 55-63.

Ibrahim, A. T. and F. L. Hall (1994): 'Effect of Adverse Weather Conditions on Speed-FlowOccupancy Relationships', Transportation Research Record, 1457, 184-191.

IPCC (2007): Climate Change 2007: Impacts, Adaptation and Vulnerability. Contribution of Working Group II to the Fourth Assessment Report of the Intergovernmental Panel on Climate Change, Cambridge University Press, Cambridge, UK. 
Khattak, A. J., P. Kantor, and F. M. Council (1998): 'Role of Adverse Weather in Key Crash Types on Limited-Access Roadways: Implications for Advanced Weather Systems', Transportation Research Record, 1621, 10-19.

Lancaster, T. (1990): The Econometric Analysis of Transition Data, Cambridge University Press, Cambridge, U.K.

Maze, T. H., M. Agarwal, and G. Burchett (2006): 'Whether Weather Matters to Traffic Demand, Traffic Safety, and Traffic Operations and Flow', Transportation Research Record, 1948, 170-176.

Rietveld, P., B. Zwart, B. van Wee, and T. van den Hoorn (1999): 'On the Relationship Between Travel Time and Travel Distance of Commuters: Reported Versus Network Data in the Netherlands', The Annals of Regional Science, 33, 269-287.

Shankar, V. N., S. Chayanan, S. Sittikariya, M. Shyu, N. K. Juwa, and J. C. Milton (2004): 'Marginal Impacts of Design, Traffic, Weather, and Related Interactions on Roadside Crashes', Transportation Research Record, 1897, 156-163.

Small, A. K. (1982): 'The Scheduling of Consumer Activities: Work Trips', American Economic Review, 72, 467-479.

Small, A. K. and E. T. Verhoef (2007): The Economics of Urban Transportation, Routledge, London/New York.

Van Ommeren, J. and J. Dargay (2006): 'The Optimal Choice of Commuting Speed: Consequences for Commuting Time, Distance and Costs', Journal of Transport Economics and Policy, 40, 279-296.

Wardman, M. (1998): 'The Value of Travel time: A Review of British Evidence', Journal of Transport Economics and Policy, 32, 285-316.

Waters II, W. G. (1996): 'Values of Travel Time Savings in Road Transport Project Evaluation', in Hensher, D. A., J. King, and T. H. Oum (eds.) Proceedings of the 
Seventh World Conference in Transport Research. World Transport Research, Vol. 3, Transport Policy, Elsevier Science, Amsterdam, 213-223.

Wooldridge, J. M. (2003): Introductory Econometrics: A Modern Approach, South-Western College Publishing. 
Table 1. Analysis of logarithm of speed of car commuting trips (without interaction effects) ${ }^{\text {a,b }}$

\begin{tabular}{|c|c|c|c|c|c|c|c|c|c|c|c|c|c|c|}
\hline & \multirow{2}{*}{\multicolumn{2}{|c|}{ OLS }} & \multicolumn{4}{|c|}{ Day Specific } & \multicolumn{4}{|c|}{ Individual Specific } & \multicolumn{4}{|c|}{ Hour Specific } \\
\hline & & & \multicolumn{2}{|c|}{ Fixed Effects } & \multicolumn{2}{|c|}{ Random Effects } & \multicolumn{2}{|c|}{ Fixed Effects } & \multicolumn{2}{|c|}{ Random Effects } & \multicolumn{2}{|c|}{ Fixed Effects } & \multicolumn{2}{|c|}{ Random Effects } \\
\hline & Coeff. & S.E. & Coeff & S.E. & Coeff & S.E. & Coeff. & S.E. & Coeff & S.E. & Coeff. & S.E. & Coeff & S.E. \\
\hline \multicolumn{15}{|l|}{ Weather Variables } \\
\hline Strong Wind & -.026 & .012 & -.024 & .014 & -.024 & .013 & -.008 & .018 & -.023 & .013 & -.027 & .012 & -.026 & .011 \\
\hline Temperature $<=0{ }^{\circ} \mathrm{C}$ & .008 & .007 & .007 & .011 & .007 & .011 & .019 & .011 & .014 & .007 & .005 & .006 & .005 & .006 \\
\hline Rain & -.004 & .007 & -.006 & .008 & -.006 & .008 & -.003 & .008 & -.005 & .007 & -.004 & .006 & -.004 & .006 \\
\hline Snow & -.074 & .033 & -.064 & .036 & -.064 & .034 & .015 & .043 & -.044 & .031 & -.073 & .033 & -.073 & .029 \\
\hline Rush Hour x Rain & - & - & - & - & - & - & - & - & - & - & - & - & - & - \\
\hline Congestion $\mathrm{x}$ Rain & - & - & - & - & - & - & - & - & - & - & - & - & - & - \\
\hline \multicolumn{15}{|l|}{ Other Explanatory variables } \\
\hline Rush Hour & -.073 & .004 & -.071 & .004 & -.071 & .004 & -.035 & .005 & -.053 & .004 & - & - & -.066 & .084 \\
\hline Distance travelled (Log) & .411 & .002 & .411 & .002 & .411 & .002 & .436 & .003 & .419 & .002 & .412 & .002 & .411 & .002 \\
\hline Carpooling & -.064 & .006 & -.063 & .006 & -.063 & .006 & -.050 & .010 & -.066 & .006 & -.067 & .006 & -.067 & .005 \\
\hline Congestion & -.066 & .011 & -.066 & .011 & -.066 & .011 & -.094 & .018 & -.070 & .011 & -.064 & .011 & -.064 & .010 \\
\hline Income (Log) & .001 & .004 & .002 & .004 & .002 & .004 & - & - & -.002 & .004 & .002 & .004 & -.002 & .003 \\
\hline Gender (Males) & .035 & .005 & .035 & .005 & .035 & .004 & - & - & .028 & .006 & .039 & .005 & .039 & .004 \\
\hline Age between 30 and 40 years & -.006 & .005 & -.006 & .005 & -.006 & .005 & - & - & -.004 & .006 & -.007 & .005 & -.007 & .005 \\
\hline Age between 40 and 65 years & -.034 & .005 & -.034 & .005 & -.034 & .005 & - & - & -.032 & .006 & -.034 & .005 & -.034 & .005 \\
\hline Age greater than 65 years & -.157 & .027 & -.152 & .027 & -.154 & .026 & - & - & -.132 & .032 & -.156 & .027 & -.156 & .024 \\
\hline Very Urbanised & -.166 & .009 & -.168 & .009 & -.168 & .009 & - & - & -.168 & .011 & -.165 & .009 & -.165 & .008 \\
\hline Urbanised & -.143 & .006 & -.144 & .006 & -.144 & .006 & - & - & -.140 & .007 & -.144 & .006 & -.144 & .005 \\
\hline Moderately Urbanised & -.101 & .006 & -.101 & .006 & -.102 & .006 & - & - & -.105 & .007 & -.103 & .006 & -.103 & .005 \\
\hline Little Urbanised & -.036 & .005 & -.036 & .005 & -.036 & .005 & - & - & -.039 & .007 & -.036 & .053 & -.036 & .005 \\
\hline Weekends & .052 & .007 & - & - & .046 & .013 & - & - & .065 & .009 & .052 & .007 & .052 & .007 \\
\hline Summer & .026 & .006 & - & - & .020 & .016 & - & - & .023 & .007 & .026 & .006 & .026 & .005 \\
\hline Autumn & -.008 & .005 & - & - & -.015 & .015 & - & - & -.010 & .006 & -.008 & .005 & -.008 & .005 \\
\hline Winter & -.013 & .006 & - & - & -.015 & .016 & - & - & -.020 & .007 & -.011 & .006 & -.011 & .006 \\
\hline Constant & 2.730 & .011 & - & - & 2.720 & .036 & - & - & 2.703 & .016 & - & - & 2.709 & .056 \\
\hline $\mathrm{R}^{2}$ & & \multicolumn{2}{|c|}{.580} & \multicolumn{2}{|r|}{-} & & \multicolumn{2}{|r|}{-} & \multicolumn{2}{|c|}{.576} & \multicolumn{2}{|r|}{-} \\
\hline Standard deviation & & & \multicolumn{2}{|c|}{.401} & \multicolumn{2}{|r|}{-} & \multicolumn{2}{|c|}{.301} & \multicolumn{2}{|c|}{-} & & 402 & & - \\
\hline Number of groups & \multicolumn{2}{|c|}{$\begin{array}{c}.403 \\
-\end{array}$} & & 366 & & 366 & & 248 & & 248 & & 24 & & 24 \\
\hline Variance of random error & & - & & - & & 153 & & - & & 083 & & - & & 132 \\
\hline Variance of group specific error & & - & & - & & 009 & & - & & 079 & & - & & .032 \\
\hline Correlation between error terms & & - & & - & & 054 & & - & & 487 & & - & & 193 \\
\hline
\end{tabular}

${ }^{a}$ Bold coefficients are statistically significant at 5\%, italic coefficients are statistically significant at $10 \%$.

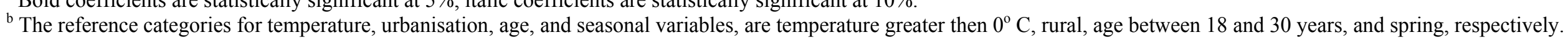


Table 2. Analysis of logarithm of speed of car commuting trips (with interaction effects) ${ }^{\text {a,b }}$

\begin{tabular}{|c|c|c|c|c|c|c|c|c|c|c|c|c|c|c|}
\hline & \multirow{2}{*}{\multicolumn{2}{|c|}{ OLS }} & \multicolumn{4}{|c|}{ Day Specific } & \multicolumn{4}{|c|}{ Individual Specific } & \multicolumn{4}{|c|}{ Hour Specific } \\
\hline & & & \multicolumn{2}{|c|}{ Fixed Effects } & \multicolumn{2}{|c|}{ Random Effects } & \multicolumn{2}{|c|}{ Fixed Effects } & \multicolumn{2}{|c|}{ Random Effects } & \multicolumn{2}{|c|}{ Fixed Effects } & \multicolumn{2}{|c|}{ Random Effects } \\
\hline & Coeff & S.E. & Coeff & S.E. & Coeff & S.E. & Coeff. & S.E. & Coef & S.E. & Coeff & S.E. & Coeff. & S.E. \\
\hline Weather Variables & & & & & & & & & & & & & & \\
\hline Strong Wind & -.026 & .013 & -.024 & .014 & -.024 & .014 & -.008 & .018 & -.023 & .013 & -.026 & .013 & -.026 & .009 \\
\hline Temperature $<=0{ }^{\circ} \mathrm{C}$ & .009 & .007 & .006 & .011 & -.007 & .010 & .019 & .012 & .014 & .007 & -.005 & .007 & -.005 & .004 \\
\hline Rain & -.015 & .012 & .013 & .012 & -.012 & .013 & .011 & .013 & .010 & .011 & .014 & .012 & .014 & .080 \\
\hline Snow & -.077 & .033 & -.065 & .036 & -.067 & .035 & .014 & .043 & -.046 & .031 & -.075 & .033 & -.075 & .022 \\
\hline Rush Hour x Rain & -.023 & .014 & -.024 & .015 & -.023 & .014 & -.012 & .016 & -.015 & .013 & -.023 & .015 & -.023 & .010 \\
\hline Congestion x Rain & -.087 & .038 & -.092 & .038 & -.092 & .037 & -.153 & .046 & -.109 & .034 & -.087 & .038 & -.087 & .025 \\
\hline Other Explanatory variables & & & & & & & & & & & & & & \\
\hline Rush Hour & -.071 & .004 & -.068 & .004 & -.069 & .004 & -.033 & .005 & -.052 & .004 & - & - & - & - \\
\hline Distance travelled (Log) & .411 & .002 & .411 & .002 & .411 & .002 & .436 & .003 & .419 & .002 & .412 & .002 & .411 & .001 \\
\hline Carpooling & -.064 & .006 & -.063 & .006 & -.063 & .006 & -.050 & .010 & -.066 & .006 & -.068 & .006 & -.068 & .004 \\
\hline Congestion & -.058 & .012 & -.058 & .011 & -.058 & .011 & -.081 & .019 & -.060 & .012 & -.056 & .012 & -.056 & .008 \\
\hline Income (Log) & .001 & .004 & .002 & .004 & .002 & .004 & - & - & .002 & .005 & .002 & .004 & -.002 & .003 \\
\hline Gender (Males) & .035 & .005 & .035 & .005 & .035 & .004 & - & - & .028 & .006 & .039 & .005 & .039 & .003 \\
\hline Age between 30 and 40 years & -.006 & .005 & -.006 & .005 & -.006 & .005 & - & - & -.004 & .006 & -.008 & .005 & -.008 & .004 \\
\hline Age between 40 and 65 years & -.034 & .005 & -.034 & .005 & -.034 & .005 & - & - & -.032 & .006 & -.034 & .005 & -.034 & .003 \\
\hline Age greater than 65 years & -.156 & .027 & -.151 & .027 & -.154 & .026 & - & - & -.131 & .032 & -.155 & .027 & -.156 & .018 \\
\hline Very Urbanised & -.166 & .009 & -.168 & .009 & -.168 & .009 & - & - & -.164 & .011 & -.165 & .009 & -.165 & .006 \\
\hline Urbanised & -.143 & .006 & -.144 & .006 & -.143 & .006 & - & - & -.140 & .007 & -.144 & .006 & -.144 & .004 \\
\hline Moderately Urbanised & -.102 & .006 & -.101 & .006 & -.101 & .006 & - & - & -.104 & .007 & -.103 & .006 & -.103 & .004 \\
\hline Little Urbanised & -.036 & .005 & -.035 & .005 & -.036 & .005 & - & - & -.038 & .007 & -.036 & .005 & -.036 & .004 \\
\hline Weekends & .052 & .007 & - & - & .046 & .013 & - & - & .065 & .009 & .052 & .007 & .052 & .005 \\
\hline Summer & .026 & .006 & - & - & .020 & .016 & - & - & .024 & .007 & .026 & .006 & .026 & .004 \\
\hline Autumn & -.007 & .005 & - & - & -.015 & .015 & - & - & -.009 & .006 & -.008 & .005 & -.008 & .004 \\
\hline Winter & -.013 & .006 & - & - & -.015 & .016 & - & - & -.020 & .007 & -.012 & .006 & -.012 & .004 \\
\hline Constant & 2.729 & .011 & - & - & 2.718 & .036 & - & - & 2.712 & .042 & - & - & 2.688 & .066 \\
\hline$\overline{\mathrm{R}^{2}}$ & & 573 & & 580 & & - & & 84 & & - & & 576 & & - \\
\hline Standard deviation & & 403 & & 401 & & - & & 00 & & - & & 402 & & - \\
\hline Number of groups & & - & & 66 & & 66 & & 248 & & 248 & & 24 & & 24 \\
\hline Variance of random error & & - & & - & & 153 & & - & & 083 & & - & & 071 \\
\hline Variance of group specific error & & - & & - & & 09 & & - & & 079 & & - & & 918 \\
\hline Correlation between error terms & & - & & - & & 55 & & - & & 488 & & - & & 564 \\
\hline
\end{tabular}

${ }^{a}$ Bold coefficients are statistically significant at 5\%, italic coefficients are statistically significant at $10 \%$.

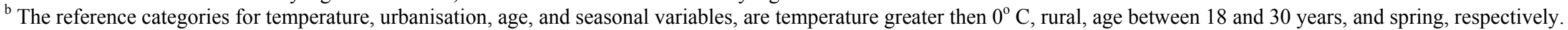




\section{Appendix A}

Table A.1. Descriptive statistics of variables used in the empirical model

\begin{tabular}{|c|c|c|}
\hline & Mean & S.D. \\
\hline \multicolumn{3}{|l|}{ Continuous Variables } \\
\hline Speed (km/hour) & 43.9 & 31.9 \\
\hline Income (in 000's Euro) & 14.2 & 5.04 \\
\hline Income $(\log )$ & 2.65 & 1.62 \\
\hline Distance (in km) & 20.1 & 25.5 \\
\hline Distance (log) & 2.41 & 1.14 \\
\hline Commuting time (in hours) & .409 & .376 \\
\hline Commuting time, non-congested roads (in hours) & .39 & .36 \\
\hline Commuting time, congested roads, rush hours (in hours) & .73 & .46 \\
\hline \multicolumn{3}{|l|}{ Dummy variables } \\
\hline Strong Wind & .024 & \\
\hline Temperature $<=0^{\circ} \mathrm{C}$ & .166 & \\
\hline Rain & .091 & \\
\hline Snow & .004 & \\
\hline Congestion & .033 & \\
\hline Rush hour & .660 & \\
\hline Carpooling & .114 & \\
\hline Males & .699 & \\
\hline Age between 18 and 30 years & .242 & \\
\hline Age between 30 and 40 years & .299 & \\
\hline Age between 40 and 65 years & .448 & \\
\hline Age greater than 65 years & .005 & \\
\hline Very Urbanised & .058 & \\
\hline Urbanised & .190 & \\
\hline Moderately Urbanised & .224 & \\
\hline Little Urbanised & .277 & \\
\hline Rural & .251 & \\
\hline Weekends & .077 & \\
\hline Spring & .262 & \\
\hline Summer & .215 & \\
\hline Autumn & .253 & \\
\hline Winter & .270 & \\
\hline Rush Hour x Rain & .062 & \\
\hline Congestion $\mathrm{x}$ Rain & .003 & \\
\hline
\end{tabular}

